\title{
USING A DESIGN ONTOLOGY TO IDENTIFY THE TERMS THAT REPRESENT THE DESIGN RESULTS ACROSS RESEARCH COMMUNITIES
}

\author{
Rosa, Maiara; Rozenfeld, Henrique \\ São Carlos School of Engineering, University of São Paulo
}

\begin{abstract}
This paper is contextualized in a research project that aims to create a new paradigm to support the design process, substituting the sequential nature of design process models by a flexible structure. To implement this paradigm, we must identify the final and intermediate results of the design process, such as documents, models, artefacts, among others. However, design research is wide and multidisciplinary, resulting in non-uniformity of the terminology across research communities, what hinders the results identification by means of a literature review. This paper aims to identify the terms employed by different research communities to refer to the intermediate and final results of the design process, structuring synonym terms across research communities and establishing how those terms interrelate in the design ontology. Using literature review, the following terms were analysed: design objects, elements, deliverables, entities, information, components, data, and artefacts. The results provide a holistic view of how the terms are employed throughout research communities, supporting the creation of search strings and pointing out opportunities for improving the design ontology.
\end{abstract}

Keywords: Design process, Terminology, Ontologies, Product modelling / models, Design ontology

\section{Contact:}

Rosa, Maiara

University of São Paulo

Production Engineering

Brazil

maiara.rosa@usp.br 


\section{INTRODUCTION}

Traditionally, the manufacturing industry employs design process models as a reference to describe or prescribe design based on best practices and methods (Browning et al., 2006). Using a design process model has been proved to be a good practice, differentiating the best companies from the others (Markham and Lee, 2013). However, this good practice still has weaknesses. First, excessive rigidity of process models may hinder innovation and creativity (Browning et al., 2006). For agile development of innovative projects, those process models may even be useless (Conforto and Amaral, 2015). Second, there are two approaches to establish a specific design process for a company: systematizing and modeling how the work is done or adapting design reference models, such as the ones proposed by Pahl et al. (2007) and Cooper (2001). On the latter approach, design reference models must be modified, demanding extra effort from the company to adapt them to its context and environment (Costa et al., 2017; Gericke and Blessing, 2011; Hollauer et al., 2017). Third, differently from operational business processes, which are repetitive and highly predictable, the design process is creative, dynamic, and often fuzzy, being characterized by iterations, rework and jumps (Vajna, 2005). The current design process models do not support developers in dealing with those characteristics (Hollauer et al., 2017).

To overcome those problems, Costa et al. (2015) state that it is necessary to focus on the flexibility of reference models. However, few studies deal with this need, such as the propositions from Freisleben and Vajna (2002), and Vajna (2005). They propose that it is possible to structure a high variety of specific design process models by combining a limited variety of design process building blocks. In their proposition, those building blocks are based on design activities, and they are used to support companies on modeling, navigating, and optimizing their existent design process. However, we believe that this rationale can also be employed for creating new flexible design process models and supporting the agile paradigm.

This paper is part of a more comprehensive research project, which is based on a rationale similar to the one presented by Freisleben and Vajna (2002), and Vajna (2005), i.e., combining design process building blocks (BBs) to structure process models instead of adapting generic design process models. Differently from the proposals of Freisleben and Vajna (2002), and Vajna (2005), the BBs of this project are structured around the design process results. The goal is to allow companies to structure specific design process models for each type of recurrent project, and, for innovative projects, to support agile development projects. However, the results of design projects have logic dependencies among themselves, i.e., it is not possible to randomly combine the BBs in any order to structure a design process model. The implementation of this paradigm requires a meta-model that states the relationships among the design process results; such as value proposition, concept, architecture, among others. To create the meta-model that may support the implementation of this new paradigm, we must identify the possible results that may derive from the design processes, which include documents, models, among other artifacts. However, this identification was hindered by the non-uniformity of the design terminology. This publication is inserted in the context of this wider project, dealing specifically with this gap.

Design is a vast and interdisciplinary topic, dealing with different perspectives and knowledge areas (Bucciarelli, 1988). Therefore, throughout the years, design research has spread around several research communities (Margolin, 2013). Each community has its terminology, including jargons and specific terms. However, ideally, any theory should be structured around a well-established set of definitions from a unified terminology (Wacker, 2008). A previous effort of unifying the design terminology into a single design ontology based on the general understanding of each term was already performed, establishing, for example, the design ontology (Štorga et al., 2010) based on the Suggested Upper Merged Ontology (Niles and Pease, 2001). This effort did not unify the design terminology - each community still employs the terms that they are used to and this fact will not be easily modified.

Therefore, to overcome the obstacle of terminology non-uniformity that was faced during the development of this research project, this paper aims to identify the terms employed by different research communities to refer to the partial and final results of the design process, structuring synonym terms and establishing how those terms interrelate. We reinforce that this paper does not aim to propose a single terminology, but to understand and schematize how each design community employs each term. We also reinforce that, even though design practitioners employ design process models, we aim to understand the terminology employed by design research communities, since the intention is to employ it for literature research purposes. 


\section{METHODOLOGY}

The purpose of this work requires gathering information on how researchers from each community deal with specific terms employed to refer to partial and final results of the design process. The first step required identifying which terms should be included in this analysis. To perform that, a systematic search based on snowballing was performed. This search started with typical classic references from design, such as the works from Pahl et al. (2007), and Simon (1969). On the classic references, we have identified which terms were commonly employed for the final and partial results of the design process. Those terms were then employed as keywords for a systematic search in the databases Scopus and Web of Science. The most cited resulting papers were analyzed, identifying other terms that they employed for referring to final and partial results of the design process. Those terms were employed in a new search string, repeating this process iteratively until no new terms were identified. After this iterative search, the terms selected for analysis were: design objects, design elements, deliverables, design entities, design information, design components, design data, and design artifacts.

The second step of this methodology was to establish a comparison structure for the terminology, creating a first overview of the selected terms based on a design ontology. Most design ontologies focus on the design process (Štorga, 2005). However, in this study, it would be necessary to select a domain ontology that focuses on the design process results instead of the process itself. Based on this requirement, the most appropriate ontology for this purpose is the one proposed by Štorga et al. (2010), which, in turn, was structured based on the epistemological ontology SUMO (Suggested Upper Merged Ontology) (Niles and Pease, 2001). The SUMO is an ontology created from the merge of "publicly available ontological content into a single, comprehensive, and cohesive structure" (Niles and Pease, 2001). The core structure of the SUMO is extracted from WordNet (Princeton University, 2010), a lexical database for English, which was developed and tested by hundreds of researchers. The structure of Wordnet, in turn, is based on semantic relationships. Three semantic relationships were considered in this analysis: hypernyms, synonyms, and hyponyms, which are explained in Table 1. Those relationships may be direct (one level up in the hierarchy) or inherited (two or more levels up in the hierarchy). We analyzed how the design-related terms were defined in the design ontology and how they interconnected through those relationships. Those results are presented in section 3.1.

Table 1. Semantic relationships employed to structure the comparison basis

\begin{tabular}{|c|c|c|}
\hline Relation & Description & Example \\
\hline Hypernym & A is a hypernym of B' means 'B is a kind of A.' & Car is a hypernym of cab \\
\hline Hyponym & A is a hyponym of B' means 'A is a kind of B.' & Cab is a hyponym of car \\
\hline Synonym & A is a synonym of B' means 'A is equal B.' & Car is a synonym of automobile \\
\hline
\end{tabular}

The third step of this methodology covers a systematic literature review (Tranfield et al., 2003) to identify how the selected terms are employed in the literature. The string combined those terms in an "OR" logic, accompanied by the term "design" in an "AND" logic, according to the following string: TITLE-ABS-KEY(("design elements" OR "design objects" OR deliverables OR "design entities" OR "design information" OR "design components" OR "design data” OR "design artifacts" OR "design artefacts") AND design).

Limiting the research to the subject areas of engineering, computer science, decision sciences, social science, multidisciplinary, and business, management, and accounting, it resulted in 17946 papers. Due to the meaningful amount of results, only the 50 most cited papers employing each term were included. For each term, the papers were categorized based on theme similarity, composing what we call in this publication as "research communities". Therefore, communities may have different levels of abstraction when comparing different terms. For some terms, the communities were broader, such as "software design". For other terms, the communities were more specific, such as "objectorientation" and "axiomatic design". After categorization, the set of selected papers was thoroughly read, understanding how each author employed and defined each one of the terms and attempting to identify patterns within and among the research communities. The results obtained are provided in section 3.2.

Finally, the usage of the terms by the distinct research communities was compared to the usage proposed by the design ontology proposed by Štorga et al. (2010). This comparison was structured in the table presented in section 3.2. 


\section{RESULTS}

\subsection{Design terminology according to the design ontology}

This section structures the design terminology covered by this paper with basis on the design ontology (Štorga et al., 2010), complementing it when necessary with the propositions of SUMO (Niles and Pease, 2001) and Wordnet (Princeton University, 2010). Figure 1 illustrates the first three levels of this structure. The figure presents the broader hypernyms to the left and the most detailed hyponyms to the right. First, the term "entity" is the broadest hypernym in SUMO, i.e., it is a term that does not belong to any group of words. Therefore, in the context of design, the term "entity" could be generically used to refer to any of its direct or inherited hyponyms. The term "entity" may regard physical entities or abstract entities - its direct hyponyms. The design ontology subdivides the possible physical entities into two groups (object and process) and the abstract entities in four groups (attribute, proposition, quantity, relation). One highlight is that the term "object" may have another meaning according to Wordnet (Princeton University, 2010), which is "the goal intended to be attained and which is believed to be attainable". This meaning is an inherited hyponym of "abstract entity". Based on this definition, it is possible to infer that the term "object" as a physical entity could be related to any tangible result of the design process, such as a prototype, a tool, or a final product, while the term "object" as an abstract entity could refer to the ultimate intent of design: a product, a service, or an organization. The term "object" as an abstract entity is relevant to the current trends of designing product-service systems, for example, which may employ the term "design object" to refer to tangible and intangible solutions.

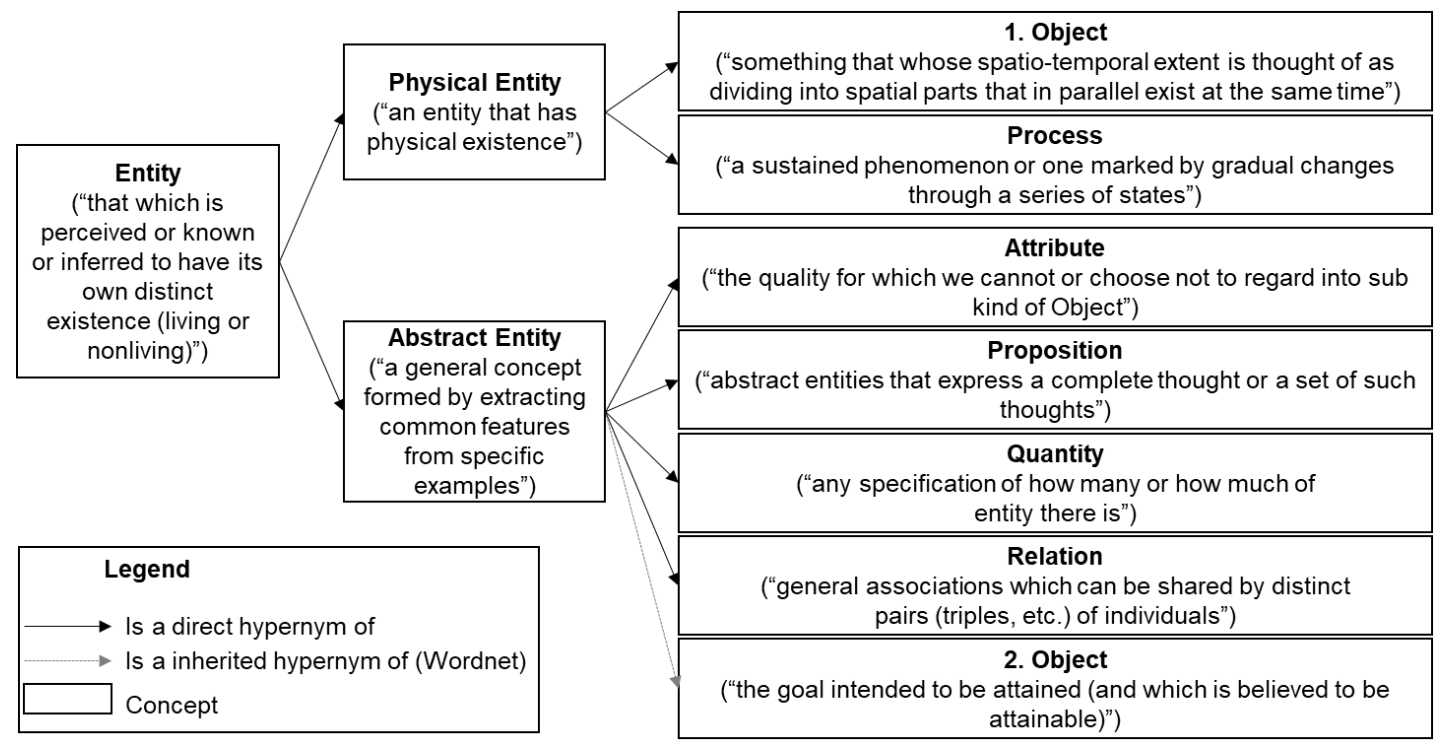

Figure 1. Meaning and semantic relationships of the terms according to the first three levels of the design ontology (Štorga et al., 2010), complemented by the meanings proposed by SUMO (Niles and Pease, 2001) and Wordnet (Princeton University, 2010)

According to the design ontology, the object as a physical artifact can be divided into four categories: biological object, material object, content-bearing object, and collection. This division, as well as its subdivisions, is illustrated in Figure 2. Only two of those categories were expanded in this paper since the others are not relevant for this discussion. First of all, the content-bearing object that is relevant to the discussion of this paper is "document". Regarding material objects, one of its direct hyponyms is "artifact", which is defined as "a man-made object taken as a whole" according to Wordnet (Princeton University, 2010). Based on this meaning, in the design context, an artifact could be considered as any physical output created by the design team, such as models, prototypes, among others - provided that they are tangible artifacts. In fact, "model" is an inherited hyponym of "artifact" according to the Wordnet structure (Princeton University, 2010). However, this connection is not contemplated in the design ontology, where the only direct hyponym of "artifact" is the term "product", which can be specified into the term "technical product". Another term that is not contemplated by the design ontology is "deliverable", which is an inherited hyponym of "product" according to Wordnet (Princeton University, 2010). However, Wordnet employs another meaning for "product". Based on SUMO, the term "deliverable" is a synonym of "product", being anything that the development team delivers during 
the development process inside the product scope. Finally, the lowest level of the object tree in the "engineering component", which refers to the parts that compose the product.

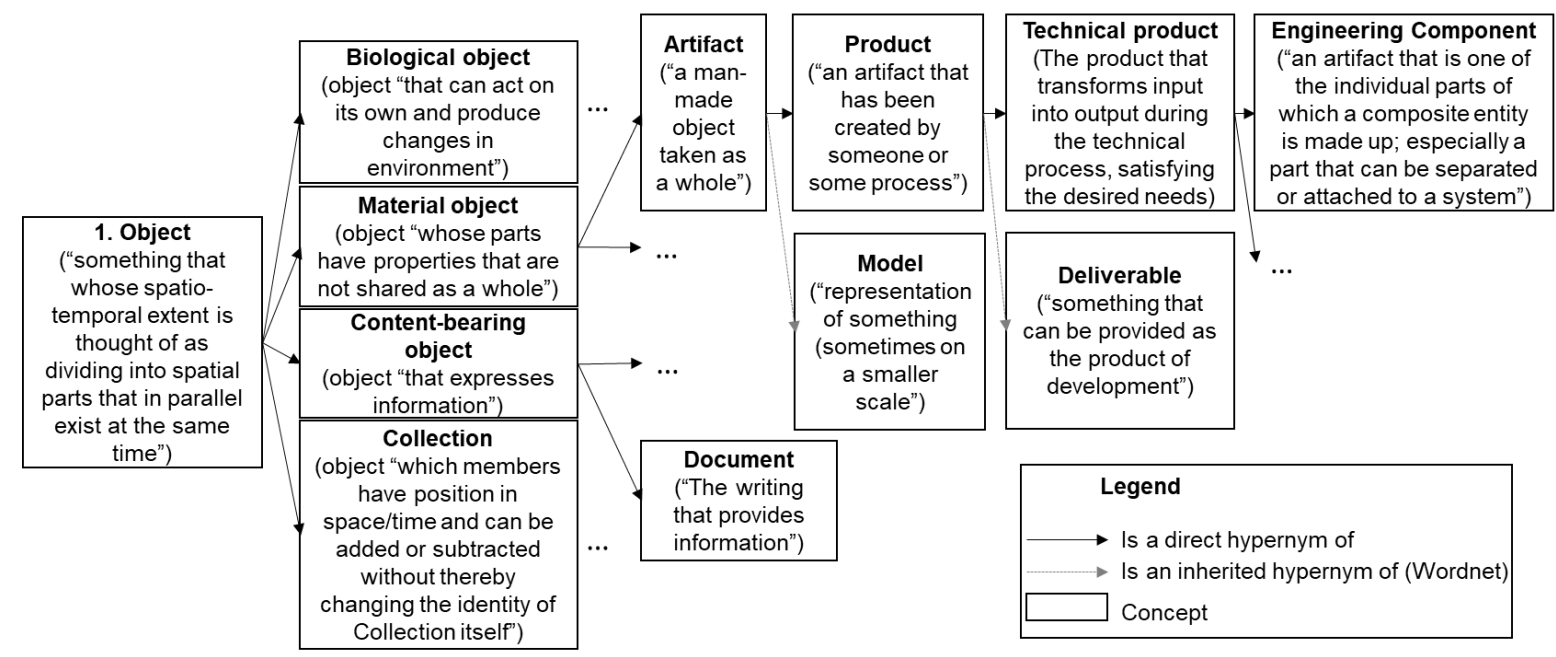

Figure 2. Meaning and semantic relationships of the terms classified as physical objects according to the design ontology (Štorga et al., 2010), complemented by the meanings proposed by SUMO (Niles and Pease, 2001) and Wordnet (Princeton University, 2010)

Figure 3 decomposes the hyponyms of the "proposition" and "relation" categories, limited to the terms that are relevant for this discussion. The explanation of this figure starts by decomposing the "proposition" category, followed by the "relation" category. One of the direct hyponyms of the proposition is the term "element", which may be a constitutional part of anything. On the same category, two direct hyponyms of "proposition" are the terms "fact", which is a direct hypernym of "data", and "information". One highlight is given to the difference between data and information. Lexically, both terms are synonyms according to Wordnet (Princeton University, 2010). However, the design ontology designates both terms as different categories.

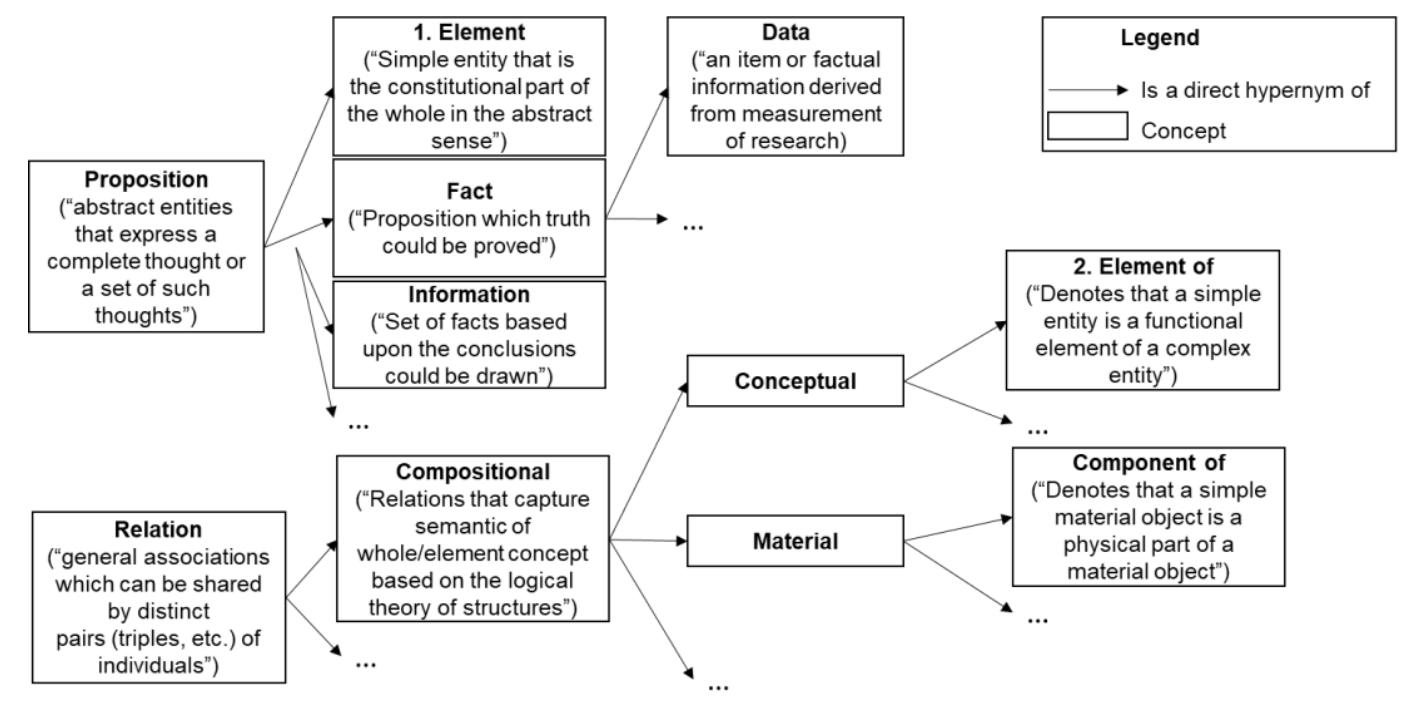

Figure 3. Meaning and semantic relationships of the terms classified as proposition and relation according to the design ontology (Štorga et al., 2010) and meanings proposed by SUMO (Niles and Pease, 2001) and Wordnet (Princeton University, 2010)

Regarding the "relation" category, Figure 3 only expands compositional relationships. Those relations can be conceptual or material, among others. The term "element" appears in the ontology for a second time. In this meaning, it refers to a relationship of a simple entity as part of a complex entity. The term "component" is also a relation here, denoting that "a simple material object is a physical part of a material object" (Štorga et al., 2010).

An overview of the terms that were presented in this section, as well as their relationships, is illustrated in Figure 4. 


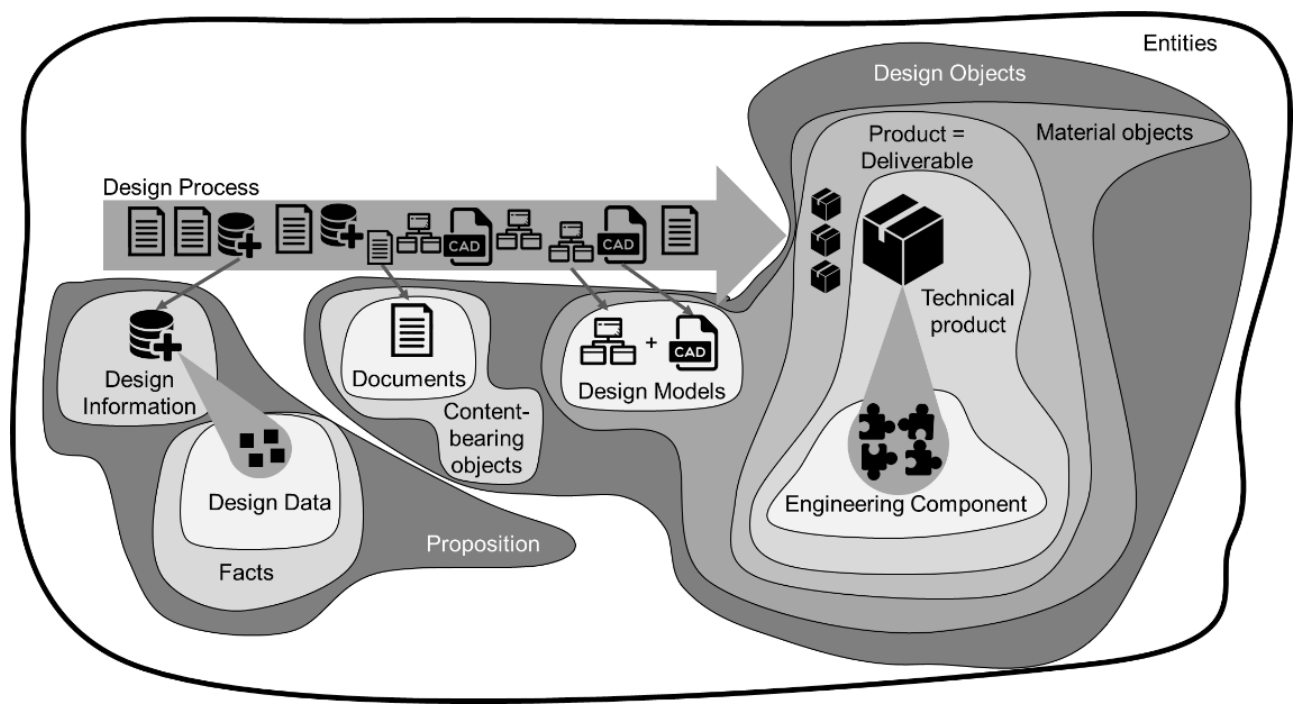

Figure 4. Representation of the structure of partial and final results of the design process

\subsection{Literature analysis of the design terminology}

Even though many publications may interchangeably use those terms, each one is more frequently employed with specific meanings by distinct research communities. This section provides a perspective of how those terms are used in the literature, which is summarized in Table 2.

Table 2. Summary of the terms meaning according to the literature review

\begin{tabular}{|c|c|c|}
\hline Term & Community & Meaning \\
\hline \multirow{3}{*}{$\begin{array}{l}\text { Design } \\
\text { entity }\end{array}$} & Object-orientation & Synonym for classes \\
\hline & Computer-Aided Design (CAD) & $\begin{array}{l}\text { 3D graphical objects, including product, assembly, } \\
\text { part, component, or feature. Partially equivalent to } \\
\text { "Design models" in the SUMO }\end{array}$ \\
\hline & $\begin{array}{l}\text { Function-Behavior-Structure } \\
\text { (FBS) }\end{array}$ & Components of design artifacts \\
\hline \multirow{2}{*}{$\begin{array}{l}\text { Design } \\
\text { information }\end{array}$} & Knowledge management & Equivalent to "information" in the SUMO \\
\hline & Software development & $\begin{array}{l}\text { Actions, decisions, and modifications during } \\
\text { software design }\end{array}$ \\
\hline \multirow{2}{*}{ Design data } & Knowledge management & Equivalent to "data" in the SUMO \\
\hline & Overall usage & Synonym of "information" in the SUMO \\
\hline \multirow{5}{*}{$\begin{array}{c}\text { Design } \\
\text { object }\end{array}$} & Computer-Aided Design (CAD) & Synonym of "product" in the SUMO \\
\hline & Feature-based design & Synonym of "product" in the SUMO \\
\hline & Systems Engineering & $\begin{array}{l}\text { Synonym of "element" in the SUMO, but regarding } \\
\text { only the system's architecture }\end{array}$ \\
\hline & Object-orientation & Identifiable conceptual entity \\
\hline & Axiomatic design & $\begin{array}{l}\text { Synonym of "object" as an abstract entity, following } \\
\text { Wordnet. }\end{array}$ \\
\hline \multirow{3}{*}{$\begin{array}{l}\text { Design } \\
\text { elements }\end{array}$} & Overall usage & $\begin{array}{l}\text { Dimensions (perspectives) that a solution may have, } \\
\text { such as provider, customer, offering. }\end{array}$ \\
\hline & Overall usage & Synonym of "Engineering components" in the SUMO \\
\hline & Overall usage & Synonym of "Design information" in the SUMO \\
\hline $\begin{array}{c}\text { Design } \\
\text { components }\end{array}$ & Overall usage & $\begin{array}{l}\text { Equivalent to "Engineering components" in the } \\
\text { SUMO }\end{array}$ \\
\hline $\begin{array}{l}\text { Design } \\
\text { artifacts }\end{array}$ & Overall usage & $\begin{array}{l}\text { Equivalent to the combination of "design models", } \\
\text { "documents" and "product" in the SUMO }\end{array}$ \\
\hline Deliverables & Overall usage & $\begin{array}{l}\text { Equivalent to the combination of "design models", } \\
\text { "documents" and "product" in the SUMO }\end{array}$ \\
\hline
\end{tabular}


The first term to be analyzed is "design entity". Probably due to its generic nature, as explained in the last section, this term is rarely employed with specific meanings in the literature. Few documents in the Scopus database employ this term in the title, abstract or keywords when compared with the other selected terms. However, a few patterns can be observed. The usage of "design entity" is well-structured in the community of software design regarding object-orientation. In this community, "entity" is often employed as a synonym for classes (Ekanayake and Kodituwakku, 2015; Marinescu, 2011). Consequently, other papers from different product design communities also employ this term with this meaning when dealing with object-orientation (Dinar et al., 2011). The CAD community, on the other hand, employs the term to refer to 3D graphical objects, including product, assembly, part, component, or feature (Jones, 2004; Krishnamurthy and Law, 1997). A pattern was also observed on papers that employ the Function-Behaviour-Structure (FBS) ontology, referring to "design entities" as the basic components of a design artifact (Jin and Benami, 2010; Kannengiesser and Gero, 2015). No other patterns were observed, even though the term "entity" was also used by punctual papers to refer to other meanings such as the product composition or the companies that perform design.

The second analysis regards the term "design information", which will be accompanied by the discussion regarding the term "design data". The terms information and data are formally differentiated in the knowledge management theory, following what is proposed in the design ontology. In this theory, data is a set of isolated facts with no associated meaning, while information is a set of facts with aggregated meaning due to relational connections (Tuomi, 1999). However, in a vast majority of times, the design literature employs the term design information as an interchangeable synonym of design data (Kim et al., 2006; Zhai et al., 2009). Despite this contradiction, the term design information is well structured. All analyzed publications that cited this term applied it with the same meaning: as a collection of facts regarding the solution that is being developed and its environment/context. This information commonly refers to the content of the design object models, such as value, cost, geometry, feasibility, budget, solution characteristics, among others (Haley et al., 2008; Komoto and Tomiyama, 2012). The only community that makes different usage of this term is the software development community, which usually employs the term design information to refer to actions, decisions, and changes that were performed during the development process (Ding et al., 2002; Reussner et al., 2003).

Regarding the term "design object," five main design research communities make extensive use of this term, employing different meanings: CAD, feature-based design, systems engineering, objectorientation, and axiomatic design. In the CAD and feature-based design research communities, the term design object mainly refers to the final result of the design process ("product" from SUMO) or by the designer's image of the product (Rosenman and Gero, 1996; Yang and Zhang, 2006). Salomons et al. (1993) explicitly criticize designers that refer to components and parts instead of the final assembly as design objects, stating that "the design object or model is the result of the design process". However, this usage is considered possible according to the design ontology, and it is not rare to find this term being employed for this purpose in those communities. In the systems engineering perspective, the meaning of "design object" stands for "a result of an architecture decision to satisfy the motivational reasons," being considered as "architecture elements classified by the data, application or technology viewpoints" (Tang et al., 2007). When dealing with object orientation, the design object is an identifiable conceptual entity with "features that span a local state space" and "operations that can change the status of the system locally", being commonly associated to hierarchical interrelationships (Gorti et al., 1998; Liang and O'Grady, 1998). Finally, in the axiomatic design community, some authors employ the term "design object" similarly to the CAD research community, however stating that they may be tangible or intangible artifacts, such as products, services, or even organizations (Harutunian et al., 1996). Additionally, some authors consider everything that appears in the design process as a design object (Zeng, 2002).

The fourth analysis of this section regards the terms "design elements" and "design components." The term component is very structured in the literature, being mainly used to refer to parts that constitute a final solution (Sauthoff et al., 2016; Sim and Duffy, 2003). On the other hand, the term "design elements" is unstructured and varied. Some authors employ this term to refer to the solution dimensions (such as offering, provider, and customer) (Ritola and Coatanéa, 2013); to engineering components, possibly extending it to other dimensions, such as aesthetics, function, and ergonomics (Noble and Kumar, 2008; Rosenman and Gero, 1996); or as a synonym for information (design ontology), citing that some of the design elements may be needs, requirements, product functions, service processes, and stakeholders networks (Kimita and Shimomura, 2012; Shimomura et al., 2015). 
Regarding the term "design artefacts", it is commonly used to refer to what we understand as a combination of design models and documents (design ontology) (Goknil et al., 2011; Wittern et al., 2012). The essence of the term "artifact" in the design theory is to describe "something that is artificial, or constructed by humans, as opposed to something that occurs naturally" (Gregor and Jones, 2007), i.e., any model, solution, or physical object created by a human is an artifact.

Finally, the term "deliverables", defined by Browning et al. (2006) as the set of "inputs, outputs, results, work products, services, information, outcomes, artifacts, items", is very uniform in the literature, being always employed with this same meaning. This term has an activity-related perspective, i.e., they are "the connectors on a flowchart that represent any information, data, result, material, etc. produced or required by an activity" (Browning et al., 2006). Usually, this term is mostly employed by the project management community (Cleland-Huang et al., 2012; Monteiro et al., 2014), by other communities employing concepts of project management (Issa and AlAli, 2011), and by the engineering education community (Pears and Daniels, 2010).

\section{CONCLUSION}

This paper has analyzed the terminology employed by the many research communities to represent the partial and final results of a design process. This analysis was based on the design ontology and the terminology's usage in the literature. An overview of the terminology and its relationships with research communities is also presented. The obtained results provide a holistic view of how each term is employed by researchers throughout research communities. The main contribution of this paper for practice and academy regards the more comprehensive project in which this publication is included. This terminology will allow us to identify the possible partial and final results of design processes, which, as explained in the introduction, will be inputs for the meta-model that supports structuring the building blocks for the new paradigm that may substitute the concept of reference design models.

Even though this paper is included in this context, we also visualize other contributions from this publication for the academy. It may support researchers who are aiming at gathering contributions from other research communities to structure search strings. Moreover, it may also support researchers on employing the most appropriate terminology for their target readers. The results also point out opportunities for complementing the design ontology with the terms that required complementation from SUMO and Wordnet. Furthermore, the terms from the design ontology that are incompatible with the overall usage in the literature also have improvement opportunities.

Adopting a common terminology would be the ideal scenario to proceed to the integration of the multiple research communities. Adequate definitions and terminologies are one of the pillar properties of a good theory (Wacker, 2008). This scenario, however, is not realistic. Each research community is already used with their daily terminology. Therefore, we reinforce here the need for efforts towards unifying the design terminology across disciplines, identifying approaches that may allow this unification.

A limitation of this publication is to approach a limited number of papers, gathering only the most cited ones, to make this research manageable. However, this decision was based on the hypothesis that, if a paper is well cited, it probably supported the research community on structuring its terminology and is well accepted by the researchers of that research community as a knowledge reference. Therefore, the concepts presented by this paper would reflect the behaviors of that given research community.

\section{ACKNOWLEDGMENTS}

The authors would like to extend sincere thanks to São Paulo Research Foundation (FAPESP), Brazilian Council for Scientific and Technological Development (CNPq), and the Higher Education Personnel Improvement Coordination (Capes) for supporting this research. This work was supported by the São Paulo Research Foundation (FAPESP) under the processes 2017/12520-0 and 2018/094749. The opinions, hypotheses and conclusions or recommendations expressed in this material are under the authors' responsibility and do not necessarily reflect the views of FAPESP.

\section{REFERENCES}

Browning, T.R., Fricke, E. and Negele, H. (2006), "Key concepts in modeling product development processes", Systems Engineering, Vol. 9 No. 2, pp. 104-28.

Bucciarelli, L.L. (1988), “An ethnographic perspective on education”, Design Studies, Vol. 9 No. 3, pp. $159-168$. 
Cleland-Huang, J., Zisman, A. and Gotel, O. (2012), "Software and systems traceability", Software and Systems Traceability, Vol. 9781447122, pp. 1-491.

Conforto, E.C. and Amaral, D.C. (2015), “Agile project management and stage-gate model - A hybrid framework for technology-based companies", Journal of Engineering and Technology Management, Elsevier B.V., Vol. 40, pp. 1-14.

Cooper, R.G. (2001), Winning at New Products: Accelerating the Process from Idea to Launch, Basic Books, New York.

Costa, D.G., Costa, J. and Rozenfeld, H. (2017), “A guide to investigating design process models context of use", Proceedings of the 21st International Conference on Engineering Design (ICED17), Vol. 2: Design, Vancouver, Canada, pp. 31-40.

Costa, D.G., Macul, V.C., Costa, J.M.H., Exner, K., Pförtner, A., Stark, R. and Rozenfeld, H. (2015), “Towards the next generation of design process models: a gap analysis of existing models", Proceedings of the 20th International Conference on Engineering Design (ICED 15) Vol 2: Design Theory and Research Methodology Design Processes, Milan, Italy.

Dinar, M., Shah, J., Langley, P., Hunt, G. and Campana, E. (2011), “A structure for representing problem formulation in design", Proceedings of the 18th International Conference on Engineering Design (ICED11), Vol. 6, Copenhagen, pp. 392-401.

Ding, Y., Ceglarek, D. and Shi, J. (2002), "Design evaluation of multi-station assembly processes by using state space approach", Journal of Mechanical Design, Vol. 124 No. 3, pp. 408-418.

Ekanayake, E.M.N.K. and Kodituwakku, S.R. (2015), "Consistency checking of UML class and sequence diagrams", 8th International Conference on Ubi-Media Computing, UMEDIA 2015, IEEE, pp. 98-103.

Freisleben, D. and Vajna, S. (2002), "Dynamic project navigation - modelling, improving, and review of engineering processes", Proceedings of DECTC'02 - ASME 2002 Design Engineering Technical Conferences and Computer and Information in Engineering Conference, Montreal, CA, pp. 1-7.

Gericke, K. and Blessing, L.T.M. (2011), "Comparisons of Design Methodologies and Process Models across disciplines: A literature review”, International Conference on Engineering Design, Kobenhavn, pp. 1-12.

Goknil, A., Kurtev, I., van den Berg, K. and Veldhuis, J.W. (2011), "Semantics of trace relations in requirements models for consistency checking and inferencing”, Software \& Systems Modeling, Vol. 10 No. 1, pp. 31-54.

Gorti, S.R., Gupta, A., Kim, G.J., Sriram, R.D. and Wong, A. (1998), “An object-oriented representation for product and design processes", Computer Aided Design, Vol. 30 No. 7, pp. 489-501.

Gregor, S. and Jones, D. (2007), "The anatomy of a design theory", Journal of the Association for Information Systems, Vol. 8 No. 5, pp. 312-335.

Haley, C.B., Laney, R., Moffett, J.D. and Nuseibeh, B. (2008), "Security requirements engineering: A framework for representation and analysis", IEEE Transactions on Software Engineering, Vol. 34 No. 1, pp. 133-153.

Harutunian, V., Nordlund, M., Tate, D. and Suh, N. (1996), "Decision making and software tools for product development based on axiomatic design theory", Annals of the CIRP, Vol. 45 No. 1, pp. 135-139.

Hollauer, C., Kattner, N. and Lindemann, U. (2017), "Towards a methodology to support the development of flexible company-specific engineering design processes", PICMET 2016 - Portland International Conference on Management of Engineering and Technology: Technology Management For Social Innovation, Proceedings, pp. 2018-2030.

Issa, A.A. and AlAli, A.I. (2011), “Automated requirements engineering: use case patterns-driven approach", IET Software, Vol. 5 No. 3, p. 287.

Jin, Y. and Benami, O. (2010), "Creative patterns and stimulation in conceptual design", Artificial Intelligence for Engineering Design, Analysis and Manufacturing, Vol. 24 No. 2, pp. 191-209.

Jones, W.T. (2004), "Toward a global parameterization for quilted CAD entities", 42nd AIAA Aerospace Sciences Meeting and Exhibit, Reno, pp. 1-10.

Kannengiesser, U. and Gero, J.S. (2015), "Is designing independent of domain? Comparing models of engineering, software and service design", Research in Engineering Design, Springer London, Vol. 26 No. 3, pp. 253-275.

Kim, K.Y., Manley, D.G. and Yang, H. (2006), "Ontology-based assembly design and information sharing for collaborative product development”, Computer Aided Design, Vol. 38 No. 12, pp. 1233-1250.

Kimita, K. and Shimomura, Y. (2012), "Design method for modular product- service system architecture", International Design Conference - Design 2012, Dubrovnik, pp. 979-988.

Komoto, H. and Tomiyama, T. (2012), "A framework for computer-aided conceptual design and its application to system architecting of mechatronics products”, Computer Aided Design, Vol. 44 No. 10, pp. 931-946.

Krishnamurthy, K. and Law, K.H. (1997), “A data management model for collaborative design in a CAD environment”, Engineering with Computers, Vol. 13 No. 2, pp. 65-86.

Liang, W.Y. and O’Grady, P. (1998), “Design with objects: An approach to object-oriented design”, CAD Computer Aided Design, Vol. 30 No. 12, pp. 943-956.

Margolin, V. (2013), "Doctoral education in design: problems and prospects”, Design Issues, Vol. 26 No. 3, pp. 70-78. 
Marinescu, C. (2011), “Are the classes that use exceptions defect prone?”, Proceedings of the 12th International Workshop and the 7th Annual ERCIM Workshop on Principles on Software Evolution and Software Evolution - IWPSE-EVOL '11, Szeged, Hungary, pp. 56-60.

Markham, S.K. and Lee, H. (2013), "Product development and management association's 2012 comparative performance assessment study", Journal of Product Innovation Management, Vol. 30 No. 3, pp. 408-429.

Monteiro, A., Mêda, P. and Poças Martins, J. (2014), "Framework for the coordinated application of two different integrated project delivery platforms", Automation in Construction, Elsevier B.V., Vol. 38, pp. 87-99.

Niles, I. and Pease, A. (2001), "Towards a standard upper ontology”, FOIS'01, Ogunquit (USA), pp. 2-9.

Noble, C.H. and Kumar, M. (2008), "Using product design strategically to create deeper consumer connections", Business Horizons, Vol. 51 No. 5, pp. 441-450.

Pahl, G., Beitz, W., Feldhusen, J. and Grote, K.-H. (2007), Engineering Design - A Systematic Approach, 3rd ed., Springer-Verlag London, London.

Pears, A. and Daniels, M. (2010), "Developing global teamwork skills: The runestone project", 2010 IEEE Education Engineering Conference, EDUCON 2010, pp. 1051-1056.

Princeton University. (2010), "WordNet", available at: http://wordnet.princeton.edu (accessed 20 August 2011).

Reussner, R.H., Schmidt, H.W. and Poernomo, I.H. (2003), "Reliability prediction for component-based software architectures", The Journal of Systems and Software, Vol. 66 No. 3, pp. 241-252.

Ritola, T. and Coatanéa, E. (2013), "Interplay between offering , provider and customer in product-service systems design”, ICED13: 19th International Conference on Engineering Design, Seoul, Korea, pp. 1-10.

Rosenman, M.A. and Gero, J.S. (1996), "Modelling multiple views of design objects in a collaborative CAD environment", CAD Computer Aided Design, Vol. 28 No. 3, pp. 193-205.

Salomons, O.W., Van Houten, F.J.A.M. and Kals, H.J.J. (1993), "Review of research in feature-based design", Journal of Manufacturing Systems, Vol. 12 No. 2, pp. 113-132.

Sauthoff, B., Gembarski, P.C. and Lachmayer, R. (2016), "Maturity-model-based design of structural components", International Design Conference - Design 2016, Dubrovnik, pp. 503-512.

Shimomura, Y., Nemoto, Y. and Kimita, K. (2015), "A method for analysing conceptual design process of product-service systems”, CIRP Annals - Manufacturing Technology, CIRP, Vol. 64 No. 1, pp. 145-148.

Sim, S.K. and Duffy, A.H.B. (2003), "Towards an ontology of generic engineering design activities", Research in Engineering Design, Vol. 14, pp. 200-223.

Simon, H. (1969), The Sciences of the Artificial, 3rd ed., The MIT Press, Massachusetts, available at:https://doi.org/10.1016/S0898-1221(97)82941-0.

Štorga, M. (2005), “THE DESIGN ONTOLOGY Contribution to the Design Knowledge Exchange and Management by The Design Ontology - Contribution to the Design Knowledge".

Štorga, M., Andreasen, M.M. and Marjanović, D. (2010), “The design ontology: Foundation for the design knowledge exchange and management”, Journal of Engineering Design, Vol. 21 No. 4, pp. 427-454.

Tang, A., Jin, Y. and Han, J. (2007), “A rationale-based architecture model for design traceability and reasoning”, Journal of Systems and Software, Vol. 80 No. 6, pp. 918-934.

Tranfield, D., Denyer, D. and Smart, P. (2003), “Towards a methodology for developing evidence-informed management knowledge by means of systematic review", British Journal of Management, Vol. 14 No. 3 , pp. 207-222.

Tuomi, I. (1999), "Data is more than knowledge: implications of the reversed knowledge hierarchy for knowledge management and organizational memory", Proceedings of the 32nd Hawaii International Conference on System Sciences, Hawaii, pp. 1-12.

Vajna, S. (2005), "Workflow for design”, Design Process Improvement: A Review of Current Practice, SpringerVerlag London Ltd, London, pp. 366-385.

Wacker, J.G. (2008), “A conceptual understanding of requirements for theory-building research: Guidelines for scientific theory building", Journal of Supply Chain Management, Vol. 44 No. 3, pp. 5-15.

Wittern, E., Schuster, N., Kuhlenkamp, J. and Tai, S. (2012), "Participatory service design through composed and coordinated service feature models", International Conference on Service-Oriented Computing, Springer Berlin Heidelberg, Berlin, pp. 158-172.

Yang, Q.Z. and Zhang, Y. (2006), "Semantic interoperability in building design: Methods and tools", CAD Computer Aided Design, Vol. 38 No. 10, pp. 1099-1112.

Zeng, Y. (2002), “Axiomatic theory of design modeling”, Journal of Integrated Design \& Process Science, Vol. 6 No. 3, pp. 1-28.

Zhai, L.Y., Khoo, L.P. and Zhong, Z.W. (2009), "Design concept evaluation in product development using rough sets and grey relation analysis”, Expert Systems with Applications, Vol. 36, pp. 7072-7079. 